\title{
A Life for Health Informatics
}

\section{Jan van Bemmel is the second recipient of the IMIA/UMIT Medical Informatics Award of Excellence}

\section{A. Geissbuhler', E. Ammenwerth ${ }^{2}$,N. Lorenzi ${ }^{3}$, S. Miksch ${ }^{4}$}

'Department of Imaging and Medical Informatics, Geneva University Hospitals, Geneva, Switzerland

${ }^{2}$ Institute for Health Information Systems, UMIT, University for Health Sciences, Medical Informatics

and Technology, Hall in Tyrol, Austria

${ }^{3}$ Vanderbilt University Medical Center, Nashville, TN, USA

${ }^{4}$ Danube University Krems, Department of Information and Knowledge Engineering, Krems, Austria

\section{Editorial}

For the second time in its history, the International Medical Informatics Association presented the IMIA/UMIT Award of Excellence, at the MEDINFO 2007 conference in Brisbane, Australia, an award sponsored by IMIA and by UMIT, the University for Health Sciences, Medical Informatics and Technology at Hall in Tyrol, Austria.

Established in 2001, this Medical Informatics Award of Excellence is given every three years to an individual whose personal commitment and dedication to medical informatics has made a lasting contribution to medicine and healthcare through her or his achievements in research, education, development or application in the field of medical informatics.

The IMIA/UMIT Award of Excellence Nominating Committee consisted of four people, two appointed to the committee by IMIA and two appointed to the committee by UMIT. Dr. Antoine Geissbuhler and Dr. Nancy Lorenzi, committee chair were appointed by IMIA. Dr. Elske Ammenwerth and Dr. Silvia Miksch were appointed by UMIT.

Nominations were requested from all IMIA members and many were received.

Professor Jan van Bemmel was unanimously selected by the commit- tee as the recipient of the second IMIA/ UMIT Medical Informatics Award of Excellence.

Born in The Netherlands in 1938, Jan van Bemmel studied physics in Delft and was soon interested by the challenges of signal processing applied to fetal electrocardiography, the topic of his $\mathrm{PhD}$ thesis. He then contributed to numerous conceptual and technological developments in the field of computerized electrocardiography analysis, and in projects that helped the evaluation and quality improvement of these tools. During the 1980's, he moved to the development of electronic health record systems, with the special interest of enabling these to support research in primary care. His research activity progressively expanded in scope to cover a wide spectrum ranging from biomedical signal processing, image processing and pattern recognition to medical and health information systems, electronic health records, and decision-support systems, resulting in more than 450 publications in scientific articles and books.

Besides his talent as a researcher, he also became an influential educator. A member of the Royal Netherlands Academy of Arts and Sciences since 1987, he helped put Medical Informatics on 
the national research and educational agenda, a mission he took forward at the international level as President of the International Medical Informatics Association, from 1998 to 2001.

His leadership and communication skills were further expressed and served the Medical Informatics community as he became the chief editor of Methods of Information in Medicine in 1987, then founded the IMIA Yearbooks of Medical Informatics series in 1992, and the Handbook of Medical Informatics in 1997.

After receiving numerous awards and distinctions, Professor Jan van Bemmel was recognized by the European Medical Informatics community in 2006 as he was elected an Honorary Member of the European Federation for Medical Informatics (EFMI), and honored during a special session where, after having been acknowledged for his lifetime contributions as an outstanding academician [1], a leading editor [2], and an efficient promoter of the Medical Informatics community internationally [3], he demonstrated his creative aptitude as he delivered a lecture full of thoughtful and cultural references [4].

The IMIA/UMIT Award of Excellence let the worldwide community of Medical Informatics salute the leading role of Professor Jan van Bemmel in developing our field at the global level.

The award celebration took place in Brisbane on August 24, 2007, during the closing ceremony of the MEDINFO
2007 Conference. Following on a tradition initiated by the recipient of the first IMIA/UMIT Award, Professor François Grémy [5], whose 2004 lecture was appropriately dubbed as a "Philosophical Promenade" [6],

Professor van Bemmel offered a lecture entitled "Reflections on Curiosity" Van Bemmel stated by saying that curiosity is characteristic for young children as well as researchers. Wondering was for Plato the core of his philosophy. Therefore he selected curiosity as his topic. Van Bemmel said that his curiosity started with astronomy and his research in biomedicine started by studying the fetal cardiovascular system, He went on to reflect on his curiosity about how human intelligence could be formalized in a computer and he used another part of his research, the interpretation of the electrocardiogram as a guide. He said, "Who could have thought at the time that I started research in the biomedical domain, now almost 45 years ago, that we would be able to look inside the body without using a surgical knife? ... Isn't it amazing that we can look in a non-invasive way at obstructions in the arterial system to prepare surgical interventions? Without the most powerful computers...it was impossible only 10 years ago. And there is much more to come." [7]

Professor van Bemmel's lecture richly explored scientific, philosophical and mystical dimensions of the quest for knowledge, illustrated by his own experiences and beliefs, and by citations from Albert Einstein, an inspiring genius. Van Bemmel said that all science is based on observations, and that all theories are man-made. A true scientist knows that his observations are confined and that he should change his theory if it better fits the observations. A genuine researcher is open for surprises, for serendipity.

Jan van Bemmel, the second recipient of the IMIA/UMIT Medical Informatics Award of Excellence is indeed a man of much curiosity and many surprises.

\section{References}

1. Hasman A, Bergemann D, McCray AT, Talmon JL, Zvárová J. Triangulation Applied to Jan H. van Bemmel. Methods Inf Med 2006;45:656-67.

2. Haux R, Hasman A, McCray AT, van der Lei J. Is Medical Informatics an Art or a Science? Methods Inf Med 2006;45:651-5.

3. Mihalas GI. Romanian Medical Informatics and Professor Jan H. van Bemmel's Support - Dr. Honoris Causa Bestowed by Victor Babes University. Methods Inf Med 2006;45:668-70.

4. van Bemmel JH. The Young Person's Guide to Biomedical Informatics. Methods Inf Med 2006;45:671-80.

5. Degoulet P, Haux R, Kulikowski C, Lun KC. François Grémy and the Birth of IMIA. 1st IMIA/ UMIT Medical Informatics Award of Excellence Given to Professor Grémy. Methods Inf Med 2005;44:349-51.

6. Grémy F. Hardware, Software, Peopleware, and Subjectivity: A Philosophical Promenade. Methods Inf Med 2005;44:352-8.

7. van Bemmel JH. Reflections on Curiosity. In: Geissbuhler A, Kulikowski C, editors. IMIA Yearbook of Medical Informatics 2008. Methods Inf Med 2008;47 Suppl 1:187-92. 